\title{
Regulation and expression of elrD1 and elrD2 transcripts during early Xenopus laevis development ${ }^{\#}$
}

\author{
FIDA NASSAR* \\ Laboratoire d'Embryologie Moléculaire et Expérimentale, UMR 8080, CNRS et Université Paris Sud, Orsay, France
}

\begin{abstract}
The Xenopus laevis elrD (elav-like ribonucleoprotein D) gene is a member of the elav/ Hu family which encodes RNA-binding proteins. Most of the elav/Hu genes are expressed in the nervous system, where they are implicated in the development and maintenance of neurons. The regulation of elrD gene expression involves two promoters, $p D 1$ and $p D 2$. In this study, we analyzed the neural specificity directed by both promoters. They were fused to the gene encoding green fluorescent protein, and their ability to drive neural expression in injected Xenopus embryos was examined. We show that both promoters direct neural expression and that whole promoter sequences are needed to induce neural specific expression. Finally, we analyzed the spatial and temporal localization of the two elrD transcripts, elrD1 and elrD2. We found that the two transcripts present the same tissue-specific pattern of expression, with distinct developmental regulation. Our results show a complex regulation of the elrD gene and suggest that different transcripts resulting from alternative splicing of the elrD gene probably define different neurons.
\end{abstract}

KEY WORDS: regulation, promoter, alternative splicing, elav, Xenopus

The elav/Hu genes constitute a multigenic family implicated in the post-transcriptional control of gene expression in neuronal cells. In Drosophila, three members of the elav/Hu have been isolated: elav (Yao et al., 1993), rbp9 (Kim and Baker, 1993) and fne (Samson and Chalvet, 2003). Members of this family have also been identified in human (Szabo et al., 1991), in the mouse (Okano and Darnell, 1997), in Xenopus (Good, 1995), in chickens (Wakamatsu and Weston, 1997), in zebrafish (Park et al., 2000) and in Caenorhabditis elegans (Fujita et al., 1999). Expression of elav/Hu genes is generally restricted to all or parts of the nervous system, except for elrB/HuB whose transcripts are also expressed in the ovary and testis and elrA/HuA whose transcripts are ubiquitously expressed (Good, 1995; Okano and Darnell, 1997; Wakamatsu and Weston, 1997).

All elav/Hu genes encodes RNA-binding proteins (RBPs) containing three RNA recognition motifs (RRMs). RRM-containing proteins are known to be involved in many post-transcriptional and translational events (Pascale et al., 2008).

In Drosophila, genetic analysis of elav suggests a role in the differentiation and maintenance of neurons (Yao et al., 1993). Consistently, overexpression of a wild type form of $\mathrm{HuB}$ or $\mathrm{HuC}$ in the mouse embryonic neural tube induces ectopic expression of neuronal markers, whereas a dominant negative form suppresses the differentiation of motor neurons (Akamatsu et al., 1999). In vitro studies also suggest the implication of ELAV/Hu proteins in neuronal differentiation. Misexpression of $\mathrm{cHuDin}$ cultured chicken neural crest cells also induces neuronal differentiation (Wakamatsu and Weston, 1997). In addition, overexpression of elrB in Xenopus embryos induces severe defects in the neural tube (Perron et al., 1999). These genes thus appear to be implicated in neuronal differentiation and or maintenance of neuronal markers.

Because all these proteins contain RRMs it is though that they may promote neuronal differentiation by regulating gene expression at a post transcriptional level (Perrone-Bizzozero and Bolognani, 2002). Consistently, Drosophila ELAV function has been shown to be important for the formation of the neuronspecific transcripts of neuroglian, erect wing and armadillo by regulating their 3'UTR (Lisbin et al., 2001; Soller and White, 2005). The Elav/Hu proteins are also implicated in regulating mRNA stability and mRNA export (Pascale et al., 2005). Indeed, HuD and HuR can decrease protein expression by inhibiting p27 translation (Kullmann et al., 2002). HuD also appears to act as a

Abbreviations used in this paper: elrD1, elav-like ribonucleoprotein D 1; elrD2, elav-like ribonucleoprotein D 2; pD1, elrD1 promoter; pD2, elrD2 promoter; GFP, green fluorescent protein.

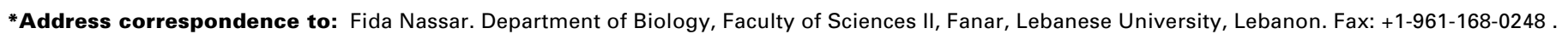
e-mail: fida.nassar@ul.edu.lb
}

\#Note: In memory of my late supervisor, Dr. Maurice Wegnez. 
major determinant of GAP-43 and Musachi 1 expression (Pascale et al., 2004; Ratti et al., 2006). Nova-1 mRNA stability and translation are strongly controlled by ELAV proteins (Ratti et al., 2008). Moreover, in Drosophila, elav autoregulates through a mechanism requiring the 3'UTR of its own mRNA (Samson, 1998). It has also been shown that fne autoregulates and interact with elav by binding the same sequences (Borgeson and Samson, 2005) and that Hu proteins can also interact with themselves (Kasashima et al., 2002).

The regulation of elav/Hu family gene expression is complex and involves alternative splicing as well as alternative promoters (Kim and Baker, 1993). We have previously characterized two alternative promoters of the elrDgene, a neural specific elav/Hu genes of Xenopus laevis (Nassar and Wegnez, 2001).

In this work, we studied the specificity of elrD1 and elrD2 promoters ( $p D 1$ and $p D 2)$ using the green fluorescent protein (GFP) as a reporter. Expression directed by each promoter construct as well as deletions promoter constructs were analyzed by microinjection into Xenopus embryos. We showed that sequential deletions in $p D 1$ and $p D 2$ constructs decrease neural expression and that both elrD transcript types, elrD1 and elrD2 are expressed specifically in the nervous system, with distinct developmental regulation

\section{Results}

\section{elrD1 and elrD2 promoter induces neural expression}

The genomic structure of elrD gene revealed a gene with two alternative promoters, $p D 1$ and $p D 2$ (Nassar and Wegnez, 2001). The elrD gene is composed of at least 5 exons and 4 introns (Fig. $1 \mathrm{~A})$ with various forms of transcripts resulting from alternative splicing (Fig. 1C). The different elrD transcripts potentially encode alternative forms of proteins with different $\mathrm{N}$-termini and an alternative splicing of exon 3 (Fig. 1D).

In order to test the neural expression of $p D 1, D 1(-1260,+62)$ and $p D 2, D 2(+405,+905)$ (Fig. 1B), we fused them to the GFP reporter gene, leading to $p D 1-G F P$ and $p D 2-G F P$ constructs. Injections of $p D 1-G F P$ and $p D 2-G F P$ constructs were performed into one dorsal or one ventral blastomere of four-cell stage embryos, knowing that the nervous system derives essentially from dorsal blastomeres. No expression of either construct was detected before stage 18 (mid neurula). GFP fluorescence was detected in the neural tube specifically in the embryos where dorsal injections of $p D$ 1-GFP and $p D 2-G F P$ were performed (Fig. 2). GFP expression appears as a mosaic due to unequal distribution of the DNA templates between cells during the course of development, but it is clearly restricted to the neural tube (Fig. 2). Embryos injected with $p E G F P-1$ (promoterless GFP), as well as those injected ventrally did not express GFP.

We also studied expression directed by $p D 1-G F P$ and $p D 2$ GFP constructs by injecting them into one blastomere at the animal pole of two-cell stage. $p D 1-G F P$ and $p D 2-G F P$ drive GFP expression in the neural tube in $52 \%$ and $58 \%$ of injected embryos respectively (Table 1). Coinjections of $p D 1-G F P$ or $p D 2-G F P$ with $S V 40-l a c Z$ constructs (lacZ gene under the control of the SV4O
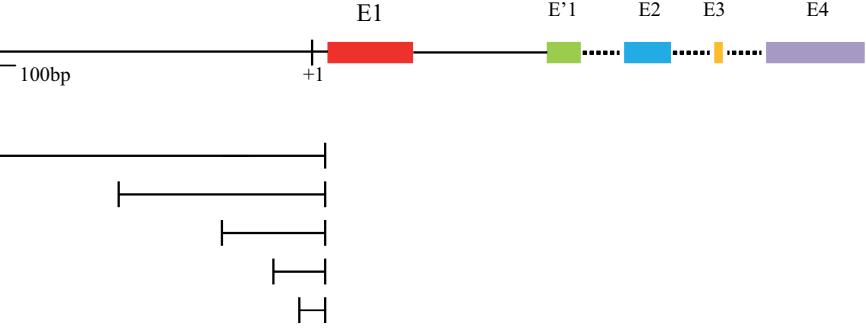

$+1$

B

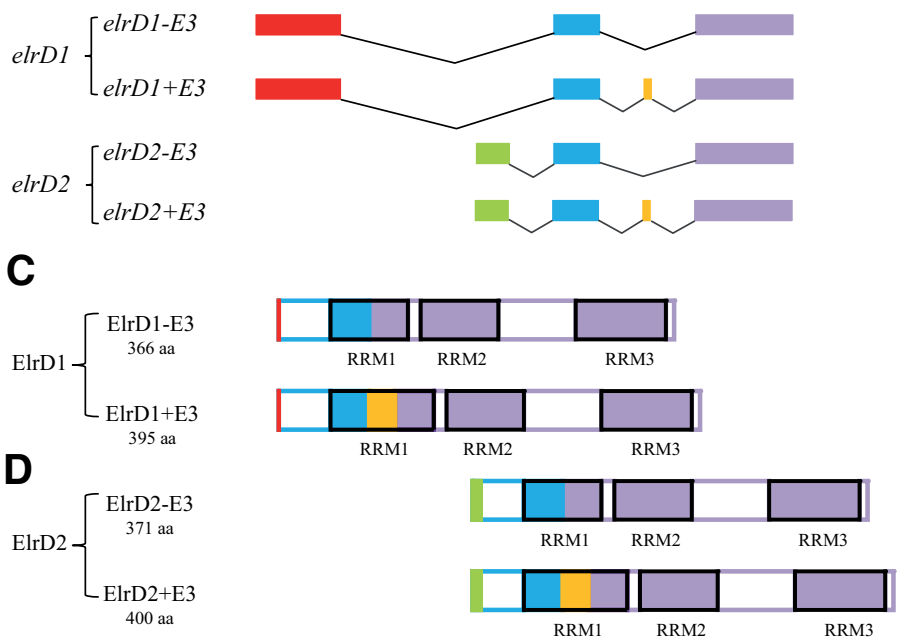

Fig. 1. Alternative promoters and splicing patterns of elrD gene. (A) Genomic structure of the elrD gene. +1 marks the position of the first nucleotide of elrD1'transcript. E1: elrD1 exon 1, E'1: elrD2 exon 1, E2: exon 2, E3: exon 3, E4: exon 4. Dashes indicate the position of introns. (B) pD1, D1 $(-1260,+62)$, and pD2, D2 $(+405,+905)$ deletion constructs. All deletions were fused to the GFP reporter gene. (C) Variants elrD transcripts. elrD1 and elrD2 have different exon 1, E1 and E'1 respectively. They share the same E2 and E4. E3 is alternatively spliced. The structure of the elrD transcripts were deduced from the structure of the elrD cDNAs. (D) Predicted ElrD protein isoforms. E1 encodes the first 3 amino acids of the ElrD1 protein while $E^{\prime} 1$ encodes the first 8 amino acids of the ElrD2 protein. E3 encodes 29 amino acids in RRM1, RNA Recognition Motif 1. The presence of intron in E4 is not determined. RRM2: RNA Recognition Motif 2. RRM3: RNA Recognition Motif 3. aa: amino acids.

promoter) were also performed. About $60 \%$ of injected embryos expressed GFP exclusively in the neural tube at the neurula stage while beta-galactosidase expression in these embryos was observed within and outside the neural tube (data not shown). These experiments confirmed that expression of GFP is restricted to the nervous system and that both $p D 1$ and $p D 2$ promoter regions are specifically regulated during early neurogenesis.

\section{Deletions in elrD1 and elrD2 promoters decrease GFP ex- pression}

In order to determine the promoter region essential to drive neural expression, four deletion constructs $D 1(-782,+62)$, D1($338,+62), D 1(-148,+62)$ and $D 1(-64,+62)$ were produced from 

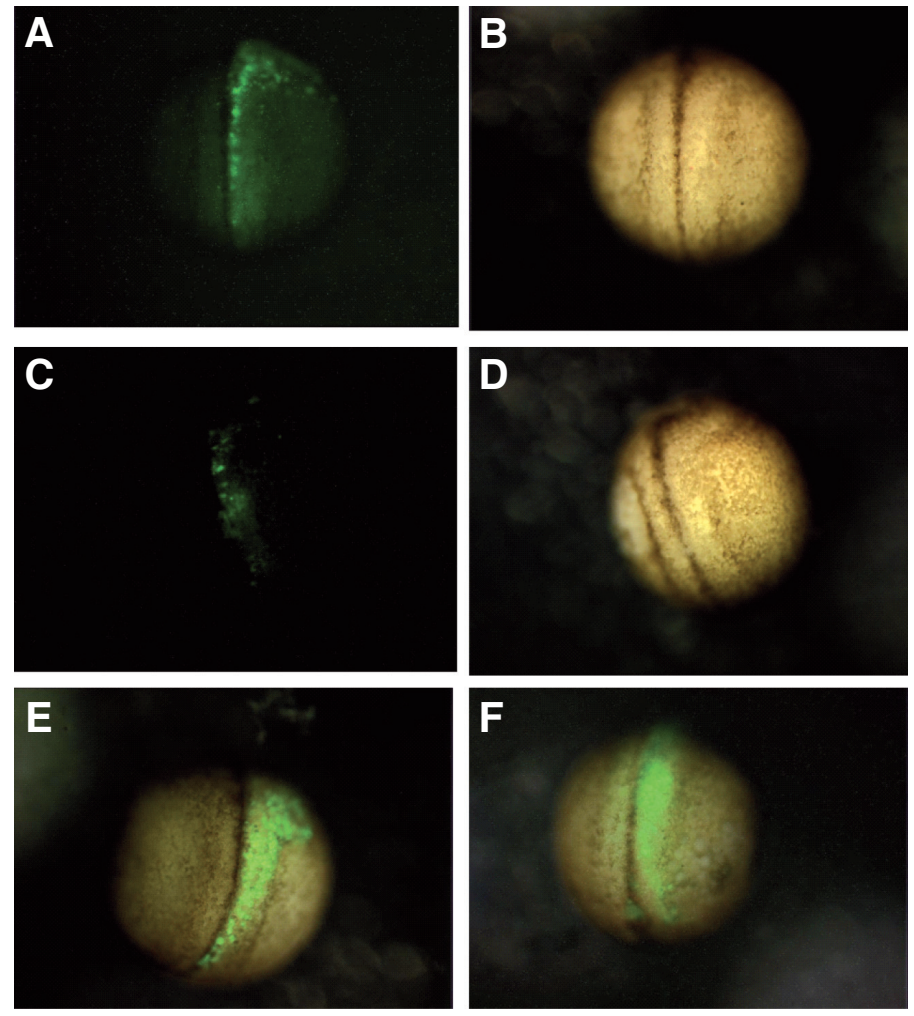

Fig. 2. Neural specificity of elrD1 and elrD2 promoters. Injected embryo with pD1-GFP (A,B) and pD2-GFP (C,D) constructs into one dorsal blastomere at four-cell stage. (A,C) Embryos under blue light. GFP expression was visualized in the neural fold at stage 18. No GFP expression was detected in the non-injected side that was used as a control (left part of the embryos). (B,D) Embryos under visible light. (E,F) Embryo expressing pD1-GFP (E) and pD2-GFP (F) constructs under visible and blue light. GFP expression is clearly visible in the neural fold.

$p D 1$ by deleting the 5 ' end of upstream elrD1 region, as well as one construct containing shorter elrD2 5' upstream region $D 2(+650,+905)$ (Fig. 1B). These constructs were fused to the GFP reporter gene and injected into one blastomere of two-cell stage embryos. No GFP fluorescence was detected for all injected constructs before neurula stage. The GFP expression begins at neurula stage in the neural tube (Table 1). The proportion of fluorescent embryos, as well as the neural tube expression, decreased when we injected constructs containing deleted 5'

TABLE 1

\section{DELETIONS IN ELRD1 AND ELRD2 PROMOTERS DECREASE THE GFP EXPRESSION}

\begin{tabular}{|c|c|c|c|c|}
\hline Construct & $\begin{array}{l}\text { Expression in the } \\
\text { nervous system }\end{array}$ & $\begin{array}{l}\text { Expression out of } \\
\text { the nervous system }\end{array}$ & No expression & $\begin{array}{c}\text { Number of } \\
\text { scored embryos }\end{array}$ \\
\hline $\begin{array}{c}p D 1 \\
D 1(-1260,+62)\end{array}$ & $52 \%$ & $8 \%$ & $40 \%$ & 394 \\
\hline$D 1(-782,+62)$ & $38 \%$ & $9 \%$ & $53 \%$ & 384 \\
\hline$D 1(-338,+62)$ & $20 \%$ & $12 \%$ & $68 \%$ & 392 \\
\hline$D 1(-148,+62)$ & $35 \%$ & $16 \%$ & $49 \%$ & 378 \\
\hline$D 1(-64,+62)$ & $8 \%$ & $15 \%$ & $77 \%$ & 390 \\
\hline $\begin{array}{c}p D 2 \\
D 2(+450,+905)\end{array}$ & $58 \%$ & $6 \%$ & $36 \%$ & 388 \\
\hline$D 2(+650,+905)$ & $5 \%$ & $13 \%$ & $82 \%$ & 398 \\
\hline
\end{tabular}

elrD1 and elrD2 upstream region (Table 1). These results show that $p D 1-G F P$ and $p D 2-G F P$ constructs drive neural specific expression during early Xenopus development. Deletions in the elrD1 and elrD2 5 ' flanking region lead to a decrease of the level and the specificity of neural-specific GFP expression.

\section{Expression of elrD1 and elrD2 transcripts}

We compared the expression of elrD1 and elrD2 transcripts at different developmental stages and in the adult brain. Since the two transcripts differ in size at their 5'ends and share the same 3'ends, we used the 5'RACE PCR to discriminate between them. No expression was found at gastrula stage (data not shown). The two transcripts were first detected at neurula stage with identical expression (Fig. 3A). Expression was also detected at tailbud stage with elrD2 stable transcripts expression stronger than elrD1. In the adult brain, expression of the two transcripts was similar (Fig. 3A). Our results show that the relative abundance of the stable elrD1 and elrD2 transcripts changes during development, revealing one specific level of regulation.

In order to determine the spatial expression of the two transcripts at the tailbud stage, we performed in situ hybridization with RNA probes specific to elrD1 and elrD2 5'UTRs (see Materials and Methods). elrD1 and'elrD2 expression was coincided and restricted to the spinal cord, the brain and the cranial ganglia (Fig. $3 \mathrm{~B}, \mathrm{C}$ ).

A

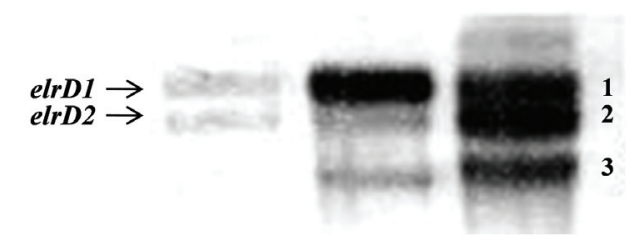

B

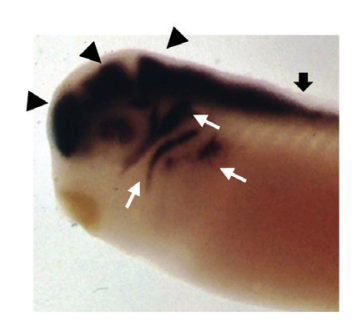

C

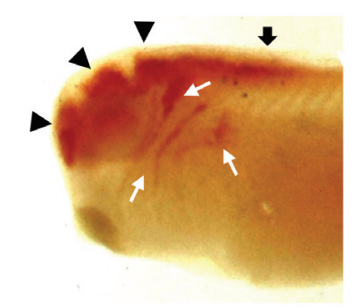

Fig. 3. Temporal and spatial expression of elrD transcripts. (A) One $\mu g$ of total RNA was reverse-transcribed and PCR performed by incorporating digoxigenin-dUTP. PCR products were resolved by electrophoresis in a 1\% agarose gel and detected as described in Materials and Methods. Sequence analysis of the cloned products has shown that bands 1 and 2 correspond to elrD1 and elrD2 transcripts, respectively. Band 3 corresponds to an incomplete elongation of elrD1 and elrD2 transcripts. N: Neurula, T: Tailbud, B: Adult Brain. (B,C) In situ hybridization at tailbud stage with an antisense elrD1 (B) and elrD2 (C) probes. expression is seen in the brain vesicles (arrowheads), the cranial ganglia (arrows) and the spinal cord (block arrow). 


\section{Discussion}

\section{Regulation of elrD gene expression by alternative promot- ers}

The elrD gene through the use of alternative promoters generates at least four alternative transcripts, predictive of four alternative protein isoforms. Deletion series in the promoter regions reveals that long sequences upstream of the start of transcription are required to direct efficient and specific neural expression of GFP reporters microinjected in embryos. In zebrafish, two GC-rich boxes were found to play a role in controlling the neuronal specific expression of $z H u C$ (Zhao et al., 2006). In Xenopus, the sequences of such boxes regulating elrD gene were not identified. Injection of neurogenin, a bHLH transcription factor, induces expression of $z \mathrm{HuC}$ (Kim et al., 1997). Little is known about the regulation of elav/Hu genes. Our results provide elements that are needed to identify specific regulators that bind to the 5' flanking region of elrD genes.

It is known that the elav gene family has evolved new functions remarkably rapidly through standard gene duplication and retrotransposition (Samson, 2008). Of particular relevance here is one of the three fly elav/Hu paralogs, rbp9, which includes 3 promoters, and produces 2 alternative forms of protein product differing by 5 residues (Kim and Baker, 1993). rbp9 produces nervous system-specific and ovaryspecific transcripts, the later being essential to female fertility (Kim-ha et al., 1999). Promoter duplication/specification might provide a mechanism for functional diversification of the elav family by changing the cell specificity of expression rather than the structure of the protein product, whether in specific cell types (elrC) or tissues ( $r b p 9)$.

\section{Alternative forms of elrD transcripts}

The elrD gene, similar to most but not all of its orthologs, is specifically expressed in the nervous system. In situ hybridization with elrD1 and elrD2 transcript-specific probes at the tailbud stage shows coincided expression in the brain, the spinal cord and the cranial ganglia.

Similar expression was described when using a RNA probe corresponding to the entire elrD $c D N A$. At this stage, elrB and elrC transcripts present the same pattern of expression as elrD (Perron et al., 1999). Nevertheless, different combinations of elav/Hu transcripts were found in subset of neurons in the mouse, zebrafish and Xenopus, suggesting that groups of neurons are defined by the expression patterns of elav/Hu (Okano and Darnell, 1996; Wakamatsu and Weston, 1997; Perron et al., 1999).

The ELAV/Hu related family Brunol/CELF genes are also differentially expressed during neurogenesis and are essential for proper neural development (Wu et al., 2010). During neurogenesis, several genes such as the Sox family of transcription factors, neurexin (nrxn), and CRMPgene also present differential expression pattern suggesting differential regulation (Cunningham et al., 2008; Souopgui et al., 2007; Zeng-et al., 2006).

The different elrD transcripts potentially encode alternative forms of proteins with different $\mathrm{N}$-termini and an alternative splicing of exon 3 that does not correlate with alternative promoter use. The alternative forms of elr $D$ transcripts as well as the alternative alternative EIrD protein isoforms might be specific for different neurons.
Our results suggest a complex regulation of elrD gene; not only different elav/Hu members but also alternative transcripts from a given member can possibly define different neurons. The two elrD promoters provide an interesting experimental system to identify factors that regulate the elav/Hu genes and present a tool that can be used as a marker of neural expression in Xenopus laevis embryos.

\section{Materials and Methods}

\section{Construction of GFP plasmids}

The $p D 1$ and $p D 2$ constructs were generated by PCR amplification using ed $1 /$ ed2 and ed $4 /$ ed 5 primers to give $D 1(-1260,+62)$ and $D 2(+405$, $+905)$ constructs. Smaller fragments of $p D 1$ and $p D 2$ constructs were generated using ed9/ed2, ed8/ed2, ed7/ed2, ed6/ed2 and ed10/ed5 primers, to give $D 1(-782,+62), D 1(-338,+62), D 1(-148,+62), D 1(-64$, $+62)$ and $D 2(+650,+905)$ constructs respectively. The PCR fragments were subcloned into the $p E G F P$ - 1 basic promoterless vector (Clontech), using the Hindlll and $X$ hol restriction sites present in the primers. Primers sequences are: ed1 5'-AAA ACT CGA GCA CCA TGA AGA GCA GCG ACT-3' (-1260, -1237); ed2 5'-GGG AAA GCT TGA AGC AGA GAA TGT GG-3' (+62,+43); ed4 5'-TTG TCT CGA GTT CTG TGT CTG CAC CTC TCG-3' (+405, +428); ed5 5'-CCA CAA G CT TAC ACA CAC ACA CAG TGC GCG-3' (+905, +882); ed6 5'-GCT TCT CGA GCA TGT GAA AGA TAG TCC C-3' (-64, -43); ed7 5'-AGA TCT CGA GCT TCA CTC TGC TAG AAG C-3' (-148, -127); ed8 5'-GGA CCT CGA GTA AAA CAG TTT GCA GGC T-3' (-338, -317); ed9 5'-ATA GCT CGA GGT TAA TAA TCG CAG CCC C-3' (-782,-760); ed10 5'-GGT TCT CGA GCT GTC ATT GTG TTT CTG C-3' $(+650,+671)$. The sequence of the 5'-region of elrD gene is accessible in the Genbank database under the accession no. AF329448.

\section{Microinjections}

Fertilized Xenopus eggs were dejellied in 2\% cysteine, $\mathrm{pH} 7,6$ and transferred into 0,1x modified Barth Saline (MBS), 5\% Ficoll solution. Plasmid constructs (300pg) were injected with a pressure-driven injector into the animal pole of two-cell stage embryos or into one dorsal or ventral blastomere of four-cell stage embryos. About 120 embryos were injected for each tested construct. Experiments were repeated four times. Embryos were cultured at $18^{\circ}-24^{\circ} \mathrm{C}$ in $0.1 \times$ MBS. They were staged according to Nieuwkoop and Faber (1967).

\section{Microscopy}

Embryos were observed using a Leica MZFL III stereomicroscope equipped with a GFP plus filter fluorescence device and photographed using a coolsnap camera.

\section{Detection of elrD transcripts by labeling 5'RACE PCR products with digoxygenin}

The 5' rapid amplification of cDNA ends (5'RACE) was conducted according to the procedure described in the SMART TM RACE CDNA amplification kit (Clontech). RNA was isolated from Xenopus laevis embryos and adult brains. Ten stage $10-11$ or stage 18 embryos, five stage 30 embryos (late tailbud) and three adult brains were homogenized in $1 \mathrm{ml}$ of $4 \mathrm{M}$ guanidine isothiocyanate, $0.5 \%$ sarcosyl, $25 \mathrm{Mm}$ sodium citrate, $\mathrm{pH} 7,0$. RNA was extracted with phenol/chloroforme and recovered by ethanol precipitation. Genomic DNA and polysaccharides were removed by $\mathrm{LiCl}$ precipitation. Prior to reverse transcription, the samples were treated with two units of RNAse-free DNAse I. One $\mu \mathrm{g}$ of total RNA was used as the template of MMLV reverse transcriptase Superscript II to synthesize the first strand cDNA with an oligo(dT) primer. The cDNA was tailed with dCTP and amplified by PCR using elrD-specific antisense oligonucleotide primer 5'-GGG GGC CAG GAT AAC GTC TGT TGG GGG ATT GGT AGA G-3' corresponding to the linker region between RRM2 and RRM3. This PCR was performed using a dNTP mix with $1 / 19$ 
digoxigenin-11-dUTP to dTTP ratio. 5' RACE products were separated on a $1 \%$ agarose gel and transferred to a nylon membrane. Nucleic acids were fixed by baking for $30 \mathrm{~min}$ at $80^{\circ} \mathrm{C}$. The membrane was rinsed in MAB (100 mM maleic acid, $150 \mathrm{mM} \mathrm{NaCl}$; $\mathrm{pH} 7,5)$, incubated $2 \mathrm{~h}$ in MAB, $1 \%$ BMBR and then $2 \mathrm{~h}$ in MAB, 1\% BMBR, 1/5000 antidigoxigenin antibody-alkaline phosphatase conjugate. The membrane was then washed twice in $\mathrm{MAB}, 0,3 \%$ Tween 20 and the alkaline phosphatase activity was revealed using BCIP/NBTaccording to Harland (1991). 5'RACE products were also gel-purified using the Nucleo Trap Gel Extraction kit, cloned into T/A-type PCR cloning vector PGEM-T, and sequenced.

\section{Whole mount in situ hybridization}

Whole mount in situ hybridization was performed with digoxigeninlabeled probes according to Harland (1991). The elrD1 probe corresponds to the elrD1 exon sequence ( $\mathrm{E} 1$ from +13 to +329 nucleotides from the transcription start site ts1) and elrD2 probe to elrD2 exon 1 sequence ( $E$ '1: from +917 to +1045 nucleotides from ts 1). elrD1 and elrD2 specific probes were generated by PCR using primers D1s/D1 as and D2 s/D2 as, respectively. D1s 5'-GCG GGG AAG CTT ATA TCT ACA CCC TAC TTG-3', D1as 5'-AAT TCT CGA GGA GTC TTG CTG GAC TTC G3', D2s 5'-GGG GAA GCT TTA GCA TCG CTT GCC AGC A-3', D2as 5'CAT CCT CGA GTT CAA GCC ATT CCA CTC C-3'. The PCR fragments were subcloned into pbluescript vector using the Hindlll and $\mathrm{Xhol}$ restriction sites present in the primers and then used as a template to generate anti-sense and sense RNA probes with T7 and T3 RNA polymerase, respectively. The embryos were sequentially incubated with the probes $(1 \mu \mathrm{g} / \mathrm{ml})$ and anti-digoxygenin antibody alkaline phosphatase conjugate. The alkaline phosphatase was revealed using BCIP/NBT according to Harland (1991).

\section{Acknowledgments}

We thank Djohra Hamdache for her expert technical assistance. This work was supported by grant 9918 from the Association pour la Recherche sur le Cancer (ARC).

\section{References}

AKAMATSU, W., OKANO, H.J., OSUMI, N., INOUE, T., NAKAMURA, S., SAKAKIBARA, S., MIURA, M., MATSUO, N., DARNELL, R.B. and OKANO, H. (1999). Mammalian ELAV-like neuronal RNA-binding proteins HuB and HuC promote neuronal development in both the central and the peripheral nervous systems. Proc Natl Acad Sci USA 96: 9885-9890.

BORGESON, C.D. and SAMSON, M.L. (2005). Shared RNA-binding sites for interacting members of the Drosophila ELAV family of neuronal proteins. Nucleic Acids Res 33: 6372-6383.

CUNNINGHAM, D.D., MENG, Z., FRITZSCH, B., and CASEY, E.S.-(2008). Cloning and developmental expression of the soxB2 genes, sox14 and sox21, during Xenopus laevis embryogenesis. Int. J. Dev. Biol. 52: 999-1004.

FUJITA, M., KAWANO, T., OHTA, A. and SAKAMOTO, H. (1999). Neuronal expression of a Caenorhabditis elegans elav-like gene and the effect of its ectopic expression. Biochem Biophys Res Commun 260: 646-652.

GOOD, P.J. (1995). A conserved family of elav-like genes in vertebrates. Proc Nat/ Acad Sci USA 9: 4557-4561.

KASASHIMA, K., SAKASHITA, E., SAITO, K. and SAKAMOTO, H. (2002). complex formation of the neuron-specific ELAV-like Hu RNA-binding proteins. Nucleic Acids Res 30: 4519-4526.

KIM, CH, BAE, YK, YAMANAKA, Y., YAMASHITA, S, SHIMIZU, T, FUJII, R, PARK, HC, YEO SY, HUH TL, HIBI M. and HIRANO T (1997). Overexpression of neurogenin induces ectopic expression of HuC in zebrafish. Neurosci Lett 239: 113-116.

KIM, Y.J. and BAKER, B.S. (1993). The Drosophila gene rbp9 encodes a protein that is a member of a conserved group of putative RNA binding proteins that are nervous system-specific in both flies and humans, J Neurosci 13: 1045-1056.

KIM-HA, J., KIM, J. and KIM, Y.J. (1999). Requirement of RBP9, a Drosophila Hu homolog, for regulation of cystocyte differentiation and oocyte determination during oogenesis. Mol Cell Biol 19: 2505-2514.

KULLMANN, M., GÖPFERT, U., SIEWE, B. and HENGST, L. (2002). ELAV/Hu proteins inhibit $\mathrm{p} 27$ translation via an IRES element in the p275'UTR Genes Dev 16: 3087-3099.

LISBIN, M.J., QIU, J. and WHITE, K. (2001). The neuron-specific RNA-binding protein ELAV regulates neuroglian alternative splicing in neurons and binds directly to its pre-mRNA. Genes Dev 15: 2546-2561.

NASSAR, F. and WEGNEZ, M. (2001). Characterization of two promoters of the Xenopus laevis elrD gene. Biochem Biophys Res Commun 283: 392-398.

OKANO, H.J. and DARNELL, R.B. (1997). A hierarchy of Hu RNA binding proteins in developing and adult neurons. J Neurosci 17: 3024-3037.

PARK, H.C., HONG, S.K., KIM, H.S., KIM, S.H., YOON, E.J., KIM, C.H., MIKI, N. and HUH, T.L. (2000). Structural comparison of zebrafish Elav/Hu and their differential expressions during neurogenesis. Neurosci Lett 279: 81-84.

PASCALE, A., GUSEV, P.A., AMADIO, M., DOTTORINI, T., GOVONI, S., ALKON, D.L. and QUATTRONE, A. (2004). Increase of the RNA-binding protein HuD and posttranscriptional up-regulation of the GAP-43 gene during spatial memory. Proc Natl Acad Sci USA 101: 1217-1222.

PASCALE, A., AMADIO, M., SCAPAGNINI, G., LANNI, C., RACCHI, M., PROVENZANI, A., GOVONI, S., ALKON, D.L. and QUATTRONE, A. (2005). Neuronal ELAV proteins enhance mRNA stability by a PKCalpha-dependent pathway. Proc Natl Acad Sci USA 102: 12065-12070.

PASCALE, A., AMADIO, M. and QUATTRONE, A. (2008). Defining a neuron: neuronal ELAV proteins. Cell Mol Life Sci 65: 128-140.

PERRON, M., FURRER, M.P., WEGNEZ, M. and THEODORE, L. (1999). Xenopus elav-like genes are differentially expressed during neurogenesis. Mech Dev 84: 139-142.

PERRON, M ., FURRER, M.P., WEGNEZ, M. and THÉODORE,-L. (1999). Misexpression of the RNA-binding protein ELRB in Xenopus presumptive neurectoderm induces proliferation arrest and programmed cell death. Int. $J$. Dev. Biol. 43: 295-303.

PERRONE-BIZZOZERO, N. and BOLOGNANI, F. (2002). Role of HuD and other RNA-binding proteins in neural development and plasticity. $J$ Neurosci Res 68 : 121-126.

RATTI, A., FALLINI, C., COVA, L., FANTOZZI, R., CALZAROSSA, C., ZENNARO, E., PASCALE, A., QUATTRONE, A. and SILANI, V. (2006). A role for the ELAV RNA-binding proteins in neural stem cells: stabilization of Msi1 mRNA. J Cell Sci 119: 1442-1452.

RATTI, A., FAlLINI, C., COLOMBRITA, C., PASCALE, A., LAFORENZA, U., QUATTRONE, A. and SILANI, V. (2008). Post-transcriptional regulation of neuro-oncological ventral antigen 1 by the neuronal RNA-binding proteins ELAV. J Biol Chem 283: 7531-7541.

SAMSON, M.L. (1998). Evidence for 3' untranslated region-dependent autoregulation of the Drosophila gene encoding the neuronal nuclear RNA-binding protein ELAV. Genetics 150: 723-733.

SAMSON, M.L. and CHALVET, F. (2003). found in neurons, a third member of the Drosophila elav gene family, encodes a neuronal protein and interacts with elav. Mech Dev 120: 373-383.

SAMSON, M.L. (2008). Rapid functional diversification in the structurally conserved ELAV family of neuronal RNA binding proteins. BMC Genomics 20: 392.

SOLLER, M. and WHITE, K. (2005). ELAV multimerizes on conserved AU4-6 motifs important for ewg splicing regulation. Mol Cell Biol 25: 7580-7591.

SOUOPGUI,-J., KLISCH, T.J., PIELER,-T. and HENNINGFELD, K.A.-(2007). Expression and regulation of Xenopus CRMP-4 in the developing nervous system.Int. J. Dev. Biol. 51: 339-343.

SZABO, A., DALMAU, J., MANLEY, G., ROSENFELD, M., WONG, E., HENSON, J., POSNER, J.B. and FURNEAUX, H.M. (1991). HuD, a paraneoplastic encephalomyelitis antigen, contains RNA-binding domains and is homologous to Elav and Sex-lethal. Cell 67: 325-333.

WAKAMATSU, Y. and WESTON, J.A. (1997). Sequential expression and role of Hu RNA-binding proteins during neurogenesis. Development 124: 3449-3460.

WU, J., LI,-C., ZHAO, S. and MAO, B.-(2010). Differential expression of the Brunol/ CELF family genes during Xenopus laevis early development. Int. J. Dev. Biol. 54: 209-214

YAO, K.M., SAMSON, M.L., REEVES, R. and WHITE, K. (1993). Gene elav 
ofÄDrosophila Melanogaster. a prototype for neuronal-specific RNA binding protein gene family that is conserved in flies and humans. $J$ Neurobiol 24: 723-739.

ZENG, Z., SHARPE,-C.R., SIMONS, J.P., and GÓRECKI,-D.C.-(2006). The expression and alternative splicing of alpha-neurexins during Xenopus
development.Int. J. Dev. Biol. 50: 39-46.

ZHAO, C., HE, X., TIAN, C. and MENG, A. (2006). Two GC-rich boxes in huC promoter play distinct roles in controlling its neuronal specific expression in zebrafish embryos. Biochem Biophys Res Commun 342: 214-220.

\section{Further Related Reading, published previously in the Int. J. Dev. Biol.}

See our recent Special Issue Placenta edited by Joan S. Hunt and Kent L. Thornburg at: http://www.ijdb.ehu.es/web/contents.php?vol=54\&issue=2-3

Developmental expression of Xenopus short-chain dehydrogenase/reductase 3

Richard K.T. Kam, Yonglong Chen, Sun-On Chan, Wood-Yee Chan, Igor B. Dawid and Hui Zhao Int. J. Dev. Biol. (2010) 54: 1355-1360 (doi: 10.1387/ijdb.092984rk)

Differential expression of the Brunol/CELF family genes during Xenopus laevis early development Jingyang Wu, Chaocui Li, Shuhua Zhao and Bingyu Mao Int. J. Dev. Biol. (2010) 54: 209-214

Developmental expression and regulation of the chemokine CXCL14 in Xenopus Byung-Yong Park, Chang-Soo Hong, Faraz A. Sohail and Jean-Pierre Saint-Jeannet Int. J. Dev. Biol. (2009) 53: 535-540

The expression and alternative splicing of alpha-neurexins during Xenopus development Zhihong Zeng, Colin R. Sharpe, J. Paul Simons and Dariusz C. Górecki Int. J. Dev. Biol. (2006) 50: 39-46

\section{Misexpression of the RNA-binding protein ELRB in Xenopus presumptive neurectoderm induces proliferation arrest and programmed} cell death

M Perron, M P Furrer, M Wegnez and L Théodore

Int. J. Dev. Biol. (1999) 43: 295-303

5 yr ISI Impact Factor $(2009)=3.253$

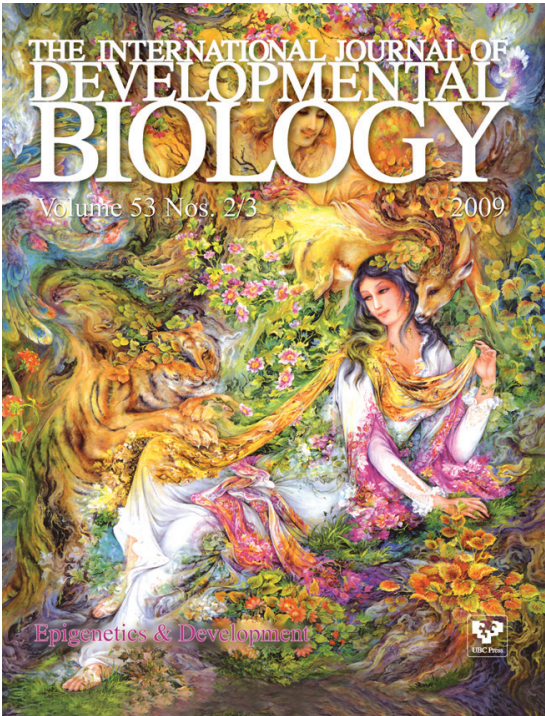

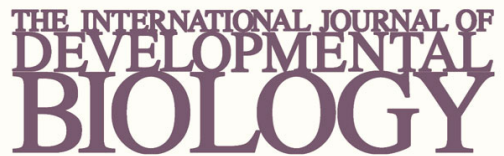

Volume 54 Nos. $6 / 7$
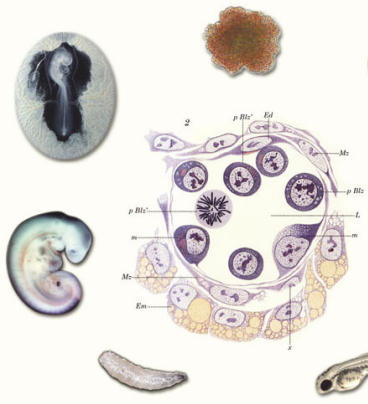

Developmental Hematopoiesis
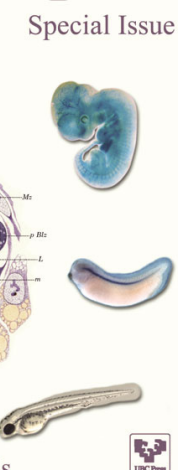

\$

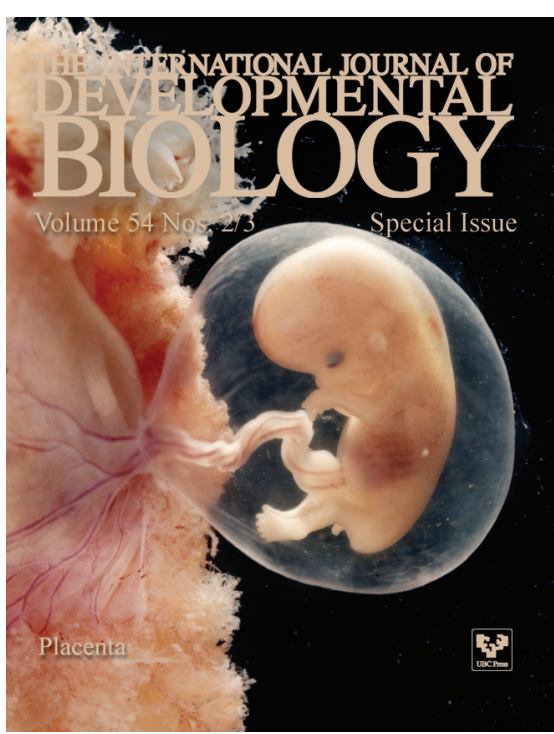

